九州大学学術情報リポジトリ

Kyushu University Institutional Repository

\title{
Soil Chemistry Effect on Feasibility of Cr- decontamination by Acid-Washing
}

Isoyama, Masahiro

Graduate School of Bioresource and Bioenvironmental Sciences, Kyushu University

Wada, Shin-Ichiro

Faculty of Agriculture, Kyushu University

https://doi.org/10.5109/4706

出版情報：九州大学大学院農学研究院紀要. 51 (1)，pp.33-36，2006-02-01. Faculty of Agriculture， Kyushu University

バージョン :

権利関係 : 


\title{
Soil Chemistry Effect on Feasibility of Cr-decontamination by Acid-Washing
}

\author{
Masahiro ISOYAMA ${ }^{1}$ and Shin-Ichiro WADA* \\ Laboratory of Soil Science, Division of Soil Science and Plant Production, Department of Plant Resources, \\ Faculty of Agriculture, Kyushu-University, Fukuoka 812-8581, Japan \\ (Received October 29, 2005 and accepted November 16, 2005)
}

\begin{abstract}
Soil washing with simple acid has been proven to be effective for removal of cationic heavy metals from contaminated soils. Since the adsorption of anionic heavy metals is enhanced in acidic medium, the efficiency of acid-washing may not be guaranteed for soils that are doubly contaminated with cationic and anionic heavy metals. To evaluate the efficiency of acid-washing, nine soils were artificially contaminated with chromate and chromium was extracted with hydrochloric acid of $0.5 \mathrm{mmol} \mathrm{L}^{-1}$ to $1 \mathrm{~mol} \mathrm{~L}^{-1}$. A part of spiked chromate was reduced to trivalent chromium and the remaining chromate ions were almost quantitatively extracted with the hydrochloric acid. However, increasing hydrochloric acid concentration was not effective for the extraction. Possible mechanisms underlying the observed low efficiency were considered to be the enhanced reduction in acidic solution, complexation by humic substance and adsorption via cation exchange reactions. We concluded that acid-washing satisfactorily works for chromate removal in non-allophanic soils but inefficient for removal of trivalent chromium particularly from soils having high effective cation exchange capacity and organic matter content.
\end{abstract}

\section{INTRODUCTION}

Contamination of soils by toxic heavy metals has been a serious environmental issue in industrial areas (Adriano, 1986). Heavy metals are retained by most of soils and the effect of pollution tends to be chronic. Typical counter measures to reduce the threat of toxicity of heavy metals are stabilization and decontamination. In the former, heavy metals are transformed into less soluble compounds or bound onto some adsorbents. In heavily contaminated soils, however, the performance of stabilization technology is usually insufficient and decontamination is needed.

Recently, many researchers tested washing with chelating agents to remove heavy metals from soils (Chen and Hong., 1995; Reed et al., 1996; Abmaizer and Smith, 1999) and proved that they are effective for decontaminating cationic heavy metals like $\mathrm{Pb}^{2+}$ and $\mathrm{Cd}^{2+}$. A problem of the method is that toxicity of the chelating agents and the increased solubility of the heavy metals that may remain in the treated soils after treatment (Page and Page, 2002). Thus the washing with simple inorganic acids is still worth further study. Isoyama and Wada (2005) washed $\mathrm{Pb}$-contaminated soils having diverse chemical and mineralogical properties and found that it is basically effective for all types of soils. They also showed that the heavy metals that remained after acid treatment are easily stabilized (unpublished).

In some sites, soils are contaminated with more than two kinds of heavy metals. For two or more cationic heavy metals, the washing with acid is expected to be equally effective if operating conditions are suitably

\footnotetext{
${ }^{1}$ Laboratory of Soil Science, Division of Soil Science and Plant Production, Department of Plant Resources, Graduate School of Bioresources and Bioenvironmental Sciences, Kyushu University

* Corresponding author (E-mail: wadasi@agr.kyushu-u.ac.jp)
}

modified. However, the situation is quite different when contaminants are combinations of cationic and anionic heavy metals. Surface complexes of cationic metals stabilize as soil pH is increased and the trend is opposite for anionic metals (Sposito, 1984). The addition of acid increases the stability of anion-soil surface complexes. In the present study nine soils contaminated with chromate $(\mathrm{Cr}(\mathrm{VI}))$ were washed with hydrochloric acid $(\mathrm{HCl})$ to remove these heavy metals. The objective of the study is to evaluate the performance of acid treatment for the removal of anionic heavy metals that may co-present with cationic heavy metals.

\section{MATERIALS AND METHODS}

Nine soil samples that differ in chemical and mineralogical properties were used in the present study. The collected soils were air-dried and passed through a $2-\mathrm{mm}$ screen. Some chemical and mineralogical properties of the soils were analyzed with standard procedures (Standard Methods of Soil Analysis Committee, 1986) and summarized in Table 1. The contents of allophane and ferrihydrite were determined by the selective dissolution with a ammonium oxalate-oxalic acid buffered at pH 3.5 (Parfitt and Wilson, 1985). Crystalline minerals in the clay fraction was identified by X-ray diffraction according to the method described by Wada and Umegaki (2001).

The soil samples were artificially contaminated with $\mathrm{Cr}(\mathrm{VI})$ by spraying $0.0192 \mathrm{~mol} \mathrm{~L}^{-1}$ potassium dichromate solution and air-drying. The amount of the sprayed solution was adjusted to make the total chromium (Cr) content $1000 \mathrm{mg} \mathrm{kg}^{-1}$. The contents of the total $\mathrm{Cr}$ and $\mathrm{Cr}(\mathrm{VI})$ were determined by hot $\mathrm{HCl}$ digestion (Asami and Kato, 1977) and $\mathrm{Na}_{2} \mathrm{CO}_{3}-\mathrm{NaOH}$ extraction and colorimetry (James et al., 1995), respectively.

Batch-washing was employed in the present study. Two gram portion of a soil sample was placed in an $85-\mathrm{mL}$ polycarbonate centrifuge tube and $10 \mathrm{~mL}$ of $\mathrm{HCl}$ 
Table 1. Selected properties of soil samples used.

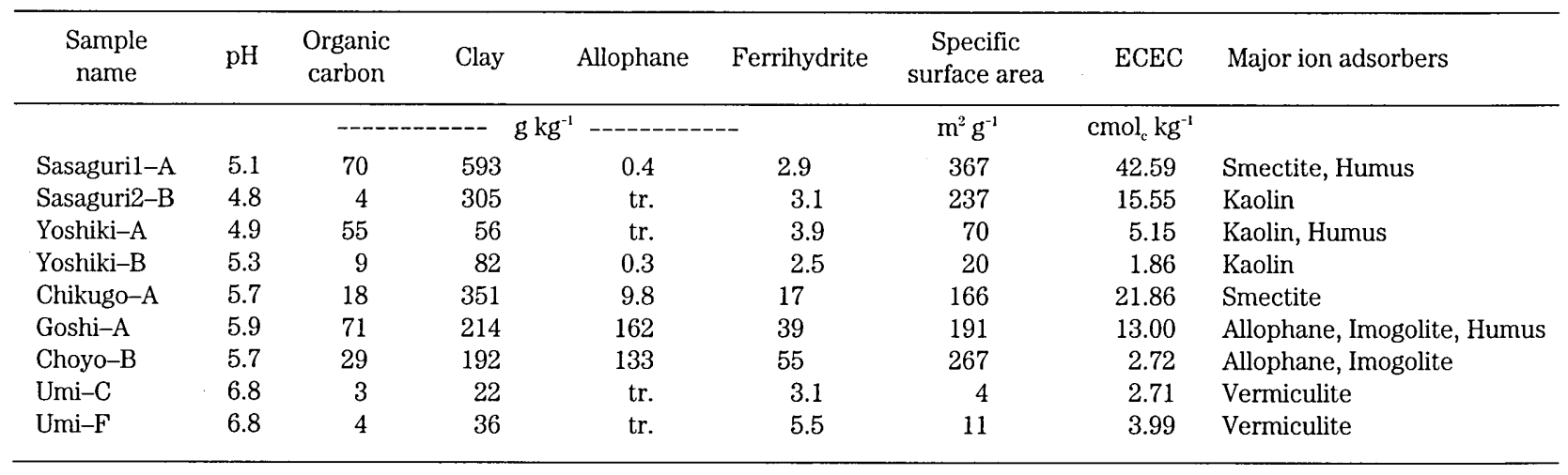

tr.; trace

was added and shaken on a reciprocal shaker for $1 \mathrm{~h}$. The tube was centrifuged and clear supernatant solution was collected for analyses of $\mathrm{pH}$ and $\mathrm{Cr}$ concentration. The $\mathrm{Cr}$ concentration was determined by an atomic absorption spectrophotometer equipped with polarized Zeeman background correction system. Similar extraction experiments were repeated with $\mathrm{HCl}$ solutions with concentrations of $0.0001,0.005,0.02,0.04,0.05,0.1,0.2$, 0.5 and $1 \mathrm{~mol} \mathrm{~L}^{-1}$.

\section{RESULTS AND DISCUSSION}

Of the nine soil samples the Choyo-B and Goshi-A samples are Andisols derived from volcanic ash. The major clay minerals of these samples are allophane and imogolite. Their contents in these soils are approximately equal. However the Goshi soil exhibits higher effective cation exchange capacity (ECEC) probably due to its higher humus content. The major clay minerals in other soils are layer silicates. The ECEC of these soils depends on both the type of layer silicate and clay content. The smectitic Chikugo-A sample shows much higher ECEC than the kaolinitic Sasaguri2-B sample. Fairly high organic matter content is the characteristics for Sasaguril-A and Yoshiki-A samples. The Choyo-B, Sasagur2-B and Goshi-A samples showed fairly high ferrihydrite content.

The $\mathrm{pH}$ and contents of the total $\mathrm{Cr}$ and $\mathrm{Cr}(\mathrm{VI})$ of the prepared soil samples are listed in Table 2. The total Cr content of the samples ranged from 859 to $1140 \mathrm{mg}$

Table 2. Total and hexavalent chromium contents and $\mathrm{pH}$ of artificially contaminated samples.

\begin{tabular}{lccc}
\hline Sample name & $\mathrm{pH}$ & Total Cr & $\mathrm{Cr}(\mathrm{VI})$ \\
\hline & & & \\
& & 941 & 6 \\
Sasaguri1-A & 5.9 & 976 & 214 \\
Sasaguri2-B & 4.9 & 859 & 19 \\
Yoshiki-A & 6.2 & 1002 & 144 \\
Yoshiki-B & 6.3 & 1077 & 209 \\
Chikugo-A & 6.2 & 1140 & 186 \\
Goshi-A & 6.2 & 1060 & 206 \\
Choyo-B & 6.1 & 992 & 512 \\
Umi-C & 6.9 & 1062 & 647 \\
Umi-F & 6.6 & & \\
\hline
\end{tabular}

$\mathrm{kg}^{-1}$ and the content of $\mathrm{Cr}(\mathrm{VI})$ was much less than the total content, indicating that the hexavalent $\mathrm{Cr}$ was partly reduced to trivalent $\mathrm{Cr}$. The reduction of $\mathrm{Cr}(\mathrm{VI})$ was conspicuous in the Sasaguril-A and Yoshiki-A samples that contained large amounts of organic matter. Approximately $20 \%$ of the total Cr remained as $\mathrm{Cr}(\mathrm{VI})$ in the Goshi sample whose organic matter content was comparable to that of the Sasaguril-A and Yoshiki-A samples. This may be due to the stabilization of chromate as surface complexes on allophane. More than half of the total Cr remained in the sandy Umi-F and Umi-C samples.

A typical reduction reaction of dichromate ion is $4 \mathrm{Cr}_{2} \mathrm{O}_{7}^{2-}+\mathrm{C}_{6} \mathrm{H}_{12} \mathrm{O}_{6}+32 \mathrm{H}^{+}=8 \mathrm{Cr}^{3+}+6 \mathrm{CO}_{2}+22 \mathrm{H}_{2} \mathrm{O}$ (1) in which 8 moles of proton are consumed in the reduction of 1 mole of dichromate ion. The rise in soil $\mathrm{pH}$ during sample preparation (Tables 1 and 2) is probably due to this reaction.

The amount of extracted $\mathrm{Cr}$ was plotted against the concentration of $\mathrm{HCl}$ in Fig. 1-a. The extracted amount of $\mathrm{Cr}$ was also plotted against solution $\mathrm{pH}$ in Fig. 1-b. The extracted amount of $\mathrm{Cr}$, in general, only gradually increased as the concentration of the added $\mathrm{HCl}$ increased above $0.1 \mathrm{~mol} \mathrm{~L}^{-1}$. Below this critical concentration, the increased concentration of the $\mathrm{HCl}$ solution had little effect on the extraction efficiency. Fig. 2 shows the relationship between the concentration of added $\mathrm{HCl}$ and the solution $\mathrm{pH}$, i. e., the acid buffer curves of the soil samples. The buffer curves show that the solution $\mathrm{pH}$ was effectively dropped from above 6 to below 2 as the concentration of the added acid increased from 0.0005 to $0.1 \mathrm{~mol} \mathrm{~L}^{-1}$. Nevertheless, there was no improvement in extraction efficiency in this acid concentration range. This is more clearly seen from the plots in Fig. 1-b, which shows that the extracted amount of $\mathrm{Cr}$ was almost constant in a $\mathrm{pH}$ range from above 6 to around 2 for all the soils.

Figs. 1 and 2 also show that the extracted amount of $\mathrm{Cr}$ greatly differed from one sample to another. The $\mathrm{Cr}$ extractions from the Umi-C and $-\mathrm{F}$ soils were higher than those of other soils in the entire concentration range. On the other hand, the Yoshiki-A and Sasaguril-A samples exhibited the lowest extraction. The amount of $\mathrm{Cr}$ extracted from the Choyo and Goshi 
samples was as low as that for the Sasaguri1-A and Yoshiki-A samples at low $\mathrm{HCl}$ concentration but it increased with increasing $\mathrm{HCl}$ concentration and approximately $50 \%$ of the total Cr was extracted in 1 mol $\mathrm{L}^{-1} \mathrm{HCl}$. The extraction patterns for the Sasaguri2-B, Yoshiki-B and Chikugo-A samples were similar in that about $200 \mathrm{mg} \mathrm{kg}^{-1}$ of $\mathrm{Cr}$ was extracted in $0.1 \mathrm{mmol} \mathrm{L}^{-1} \mathrm{HCl}$ and the extraction increased up to $400-500 \mathrm{~kg}^{-1}$ as the $\mathrm{HCl}$ concentration increased.

The comparison of Table 2 and Fig. 1 suggests that the order of extraction efficiency roughly paralleled the
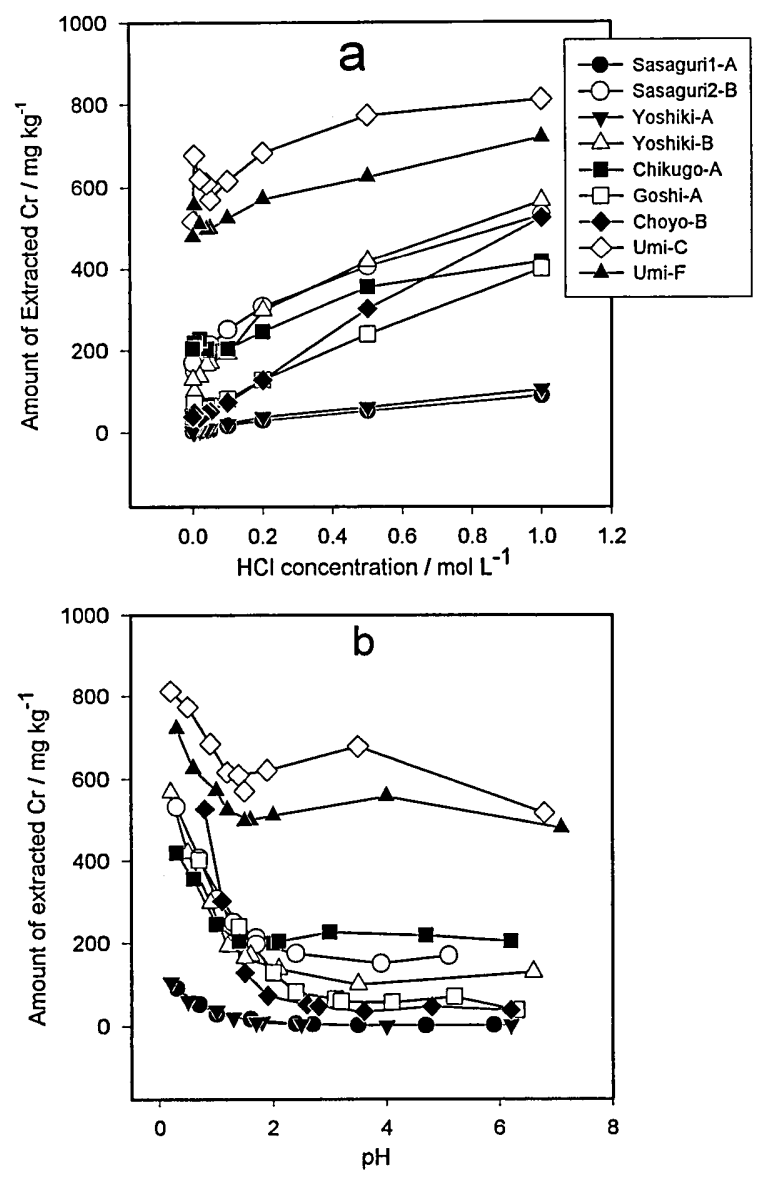

Fig. 1. Extracted amount of $\mathrm{Cr}$ as plotted against $\mathrm{HCl}$ concentrarion (a) and solution $\mathrm{pH}$ (b).

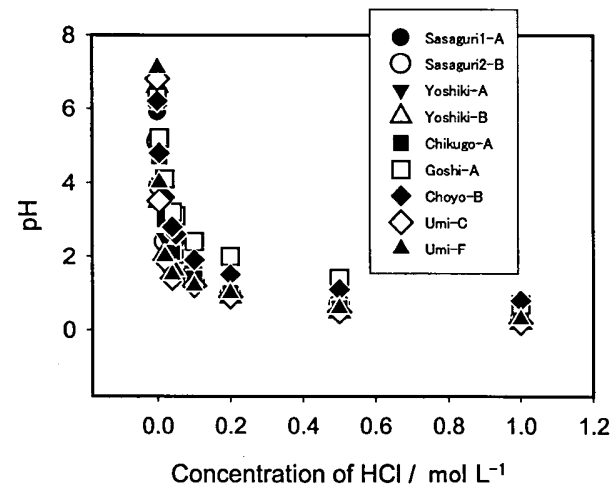

Fig. 2. Equilibrium $\mathrm{pH}$ as plotted against concentration of added $\mathrm{HCl}$. order of the Cr(VI) content. The extracted amount of

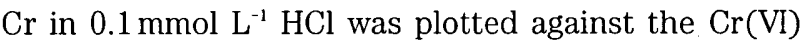
content in Fig. 3. This plot clearly shows that there is a 1:1 relationship between the extracted amount of $\mathrm{Cr}$ in $0.1 \mathrm{mmol} \mathrm{L}^{-1} \mathrm{HCl}$ and the $\mathrm{Cr}(\mathrm{VI})$ content for soil samples other than Goshi-A and Choyo-B, suggesting that $\mathrm{Cr}(\mathrm{VI})$ was almost quantitatively extracted in the dilute $\mathrm{HCl}$ at around $\mathrm{pH}$ 6. The big deviations from 1:1 relationship for the Goshi-A and Choyo-B samples are probably due to the adsorption of chromate by allophane in these soil samples.

According to previous adsorption studies (Zachara et al., 1989; Dzombak and Morel, 1990), chromate adsorption by soils and iron oxide minerals increases as $\mathrm{pH}$ decreases below 8 . Under a fixed chromate load, the adsorption starts to increase at around $\mathrm{pH} 8$ and reaches plateau at slightly below $\mathrm{pH} 7$. Since the solution $\mathrm{pH}$ of the present soil samples were in a range from 6.5 to 7 when the $0.1 \mathrm{mmol} \mathrm{L}^{-1} \mathrm{HCl}$ was added and equilibrated, all the chromate should have been adsorbed. The unexpected near complete extraction of chromate may be partly due to the competition with silicic acid (Garman et al., 2004). It is naïve to generalize the present results but Fig. 3 strongly suggest that the adsorption of chromate is not significant in non-allophanic soils.

The adsorption studies also show that the adsorption of chromium ion (Cr(III)) decreases as solution $\mathrm{pH}$ deceases. Compilation by Dzombak (1990) shows that Cr(III) adsorption via surface complexation starts to decrease at $\mathrm{pH}$ of about 5 and becomes negligible below $\mathrm{pH}$ 3. In the present experiment, however, the $\mathrm{Cr}$ extraction was nearly constant in the $\mathrm{pH}$ range from 6 to 2 (Fig. 1-b). This seemingly contradictory result may be explained by taking other adsorption mechanisms into consideration. One is the complexation by humic substances. Although there is no data on the complexation of $\mathrm{Cr}$ (III) by humic substance but similarity of $\mathrm{Cr}$ (III) to aluminum ion suggests that it forms stable complexes with humic substance. Another one is the adsorption via cation exchange reaction. Fig. 4 shows the relationship between the percentage of $\mathrm{Cr}$ extracted in $1 \mathrm{~mol} \mathrm{~L}^{-1} \mathrm{HCl}$ and ECEC, in which fairly high negative correlation is noticeable. This trend supports the view that the retention via cation exchange is a cause of the unexpectedly

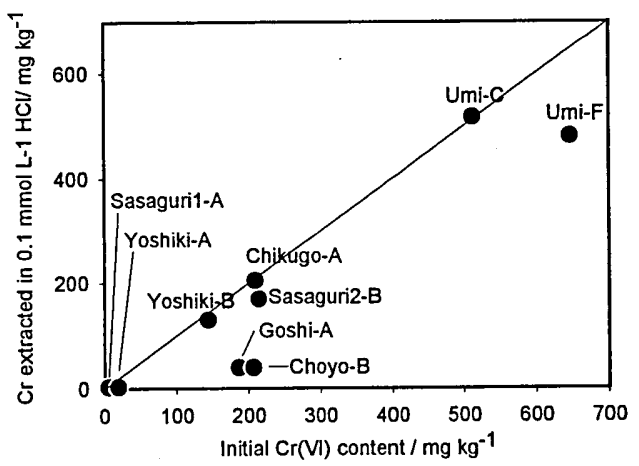

Fig. 3. Relationship between initial $\mathrm{Cr}(\mathrm{VI})$ content and amount of $\mathrm{Cr}$ extracted in $0.1 \mathrm{mmol} \mathrm{L} \mathrm{L}^{-1} \mathrm{HCl}$ 


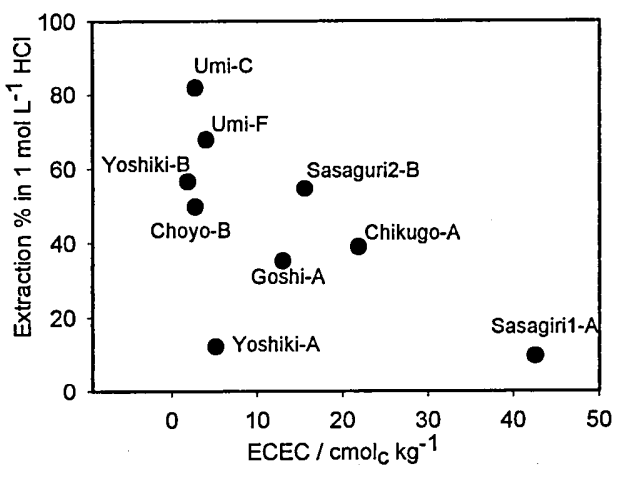

Fig. 4. Relationship between ECEC and Cr extraction percentage in $1 \mathrm{~mol} \mathrm{~L}^{-1} \mathrm{HCl}$.

low extraction. The plot point for the Yoshiki-A sample markedly deviates from the trend, suggesting that the complexation by humic substance also contributed the low extraction efficiency.

Table 2 shows that at least a part of the spiked $\mathrm{Cr}$ (VI) was reduced to $\mathrm{Cr}$ (III) during air-drying and storage in soils having $\mathrm{pHs}$ around 6 . Since the reduction reaction is favored by acidification as expected from the stoichiometry of the reaction (Eq. (1)), the reduction reaction must have advanced further during extraction at $\mathrm{pHs}<4$. This is favorable for detoxification of $\mathrm{Cr}$ because $\mathrm{Cr}(\mathrm{III})$ is much less toxic than $\mathrm{Cr}(\mathrm{VI})$. As already discussed the washing with $\mathrm{HCl}$ can effectively remove $\mathrm{Cr}(\mathrm{VI})$ at least from non-allophanic soils. The washing with acid is, therefore, effective method for at least detoxification of $\mathrm{Cr}$ in soils if not for decontamination of $\mathrm{Cr}$.

One concern is that $\mathrm{Cr}$ (III) is oxidized to $\mathrm{Cr}(\mathrm{VI})$ in some soils (Chung and Sa, 2001; Cooper, 2002; Kim and Dixon, 2002; Stepniewska et al., 2004). Mn oxide minerals were identified as oxidant of $\mathrm{Cr}$ (III) in soils and $\mathrm{Cr}$ (III) oxidation potential increases as the content of $\mathrm{Mn}$ oxides increases (Kim and Dixon, 2002). The Cr(III) oxidation by Mn oxides in soils are favored by low organic matter content and high pH (Cung and Sa, 2001). Thus, necessary conditions for suppressing $\mathrm{Cr}$ (III) oxidation do not accord with those for minimizing solubility of cationic heavy metals such as $\mathrm{Pb}^{2+}$ and $\mathrm{Cd}^{2+}$. For cationic heavy metals, soil $\mathrm{pH}$ should be maintained at 7 or above by liming to reduce the solubility of remaining heavy metals. For Mn-rich soils that are contaminated with both $\mathrm{Pb}$ and $\mathrm{Cr}$, washing with acid and subsequent liming may not be enough for reducing risk.

\section{CONCLUSIONS}

The soil washing with dilute acid could effectively remove $\mathrm{Cr}(\mathrm{V})$ from non-allophanic soils. It was, however, not effective for extracting $\mathrm{Cr}$ (III). Retention of Cr(III) on cation exchange sites and formation of stable complexes with soil organic matter are the possible causes for the low Cr(III) extraction efficiency. The acid-washing would successfully remove cationic heavy metals and $\mathrm{Cr}(\mathrm{VI})$ from multiply contaminated soils leaving most part of $\mathrm{Cr}$ (III). Since $\mathrm{Cr}$ (III) is gradually oxidized to give $\mathrm{Cr}(\mathrm{VI})$ in $\mathrm{Mn}$-rich soils at high $\mathrm{pH}$, the application of soil washing with acid and subsequent alkalinization for stabilization to such soils should be avoided.

\section{REFERENCES}

Abumaizar, R. J. and E. H. Smith 1999 Heavy metal contaminants removal by soil washing. J. Hazard. Mater., B70: 71-86

Adriano, D. C. 1986 Trace Elements in Terrestrial Environment. Springer-Verlag, New York

Asami, T and A. Kato 1977 Comparison of analytical methods for total cadmium, zinc, lead and copper in soils. Jpn. J. Soil Sci. Plant Nutr., 48: 335-336

Chen, T. -C. and A. Hong 1995 Chelating extraction of lead and copper from an authentic contaminated soil using N-(2-acetamido)iminodiacetic acid and S-carboxymethyl-L-cysteine, J. Hazard. Mater., 41: 147-160

Chung, J. B. and T. M. Sa 2001 Chromium oxidation potential and related soil characteristics in arable upland soils. Commun. Soil Sci. Plant Anal., 32: 1719-1733

Cooper, G. R. C. 2002 Oxidation and toxicity of chromium in ultramafic soils in Zimbabwe. Appl. Geochem., 17: 981-986

Dzombak, D. A. and F. M. M. Morel 1990 Surface Complexation Modeling Hydrous Ferric Oxide. John-Wiley \& Sons, New York

Garman, S. M., T. P. Luxton and M. J. Eick 2004 Kinetics of chromate adsorption on goethite in the presence of sorbed silicic acid. J. Environ. Qual., 33: 1703-1708

Isoyama, M. and S. - I. Wada 2005 Soil chemistry effect on the $\mathrm{Pb}-$ removal from contaminated soils by batch-and column-washing with hydrochloric acid. J. Hazad. Mater. Submitted

James, B. R., J. C. Petura, R. J. Vitale and G. R. Mossoline 1995 Hexavalent chromium extraction from soils: A comparison of five methods. Environ. Sci. Technol., 29: 2377-2381

Kim, J. G. and J. B. Dixon 2002 Oxidation and fate of chromium in soils. Soil Sci. Plant Nutr., 48: 483-490

Page, M. M. and C. L. Page 2002 Electroremediation of contaminated soils. J. Environ. Eng.-ASCE, 128: 208-219

Parfitt, R. L. and A. D. Wilson 1985 Estimation of allophane and halloysite in three sequences of volcanic soils, New Zealand. Catena Suppl., 7: 1-8

Reed, B. E., P. C. Carriere and R. Moore 1996 Flushing of a $\mathrm{Pb}$ (II) contaminated soil using $\mathrm{HCl}, \mathrm{EDTA}$, and $\mathrm{CaCl}_{2}, J$. Environ. Eng. $-A S C E$, 122: 48-50

Sposito, G 1984 The Surface Chemistry of Soils. Oxford University Press, New York

Standard Methods of Soil Analysis Committee 1986 Standard Methods of Soil Analysis. Haku-yu-sha, Tokyo (in Japanese)

Stepniewska, Z., K. Bucior and R. P. Bennicelli 2004 The effects of $\mathrm{MnO}_{2}$ on sorption and oxidation of $\mathrm{Cr}$ (III) by soils. Geoderma, 122: 291-296

Wada, S. -I. and Y. Umegaki 2001 Major ion and electrical potential distribution in soil under electrokinetic remediation. Environ. Sci. Technol., 35: 2151-2155

Zachara, J. M., C. C. Ainsworth, C. E. Cowan and C. T. Resch 1989 Adsorption of chromate by subsurface soil horizons. Soil Sci. Soc. Am. J., 53: 418-428 